\title{
A FRAND Regime for Dominant Digital Platforms
}

\author{
by Mathew Heim and Igor Nikolic*
}

\begin{abstract}
Dominant digital platforms are under increased scrutiny by regulators around the world, notably competition authorities. Much of the discussion focuses on market access and contestability. However, many doubt whether traditional competition law enforcement can, by itself, be an adequate solution to the challenges posed by dominant digital platforms. Instead, a broader regulatory solution could be devised to ensure effective competition and to provide access to critical platforms or access to data. On the premises that regulation is warranted, this paper considers whether a Fair, Reasonable and Non-Discriminatory (FRAND) access regime could be a solution to ensure effective competition, while maintaining the incentives of dominant platforms to
\end{abstract}

\begin{abstract}
innovate. The paper shows that, beyond the application of FRAND in the competition law context, the European Union institutions have consistently used the FRAND regime to ensure access to critical infrastructure or inputs. The FRAND regime has been applied in EU legislation such as standardisation, chemicals, electronic communications framework, public sector information, research framework, vehicles emissions, payment services, credit rating agencies and benchmark regulations. It has proved itself to be a flexible and pragmatic tool, able to apply to different market dynamics and bottlenecks. Drawing out the common elements of this European FRAND access regime, the paper considers how it could be applied as a regulatory solution for dominant digital platforms.
\end{abstract}

(๑) 2019 Mathew Heim and Igor Nikolic

Everybody may disseminate this article by electronic means and make it available for download under the terms and conditions of the Digital Peer Publishing Licence (DPPL). A copy of the license text may be obtained at http://nbn-resolving. de/urn:nbn:de:0009-dppl-v3-en8.

Recommended citation: Mathew Heim and Igor Nikolic, A FRAND Regime for Dominant Digital Platforms, 10 (2019) JIPITEC 38 para 1.

\section{A. Introduction}

1 The European Commission is considering what role competition policy may play in addressing concerns linked to the market power of digital platforms. ${ }^{1}$ The question is apposite, given that digital platforms

* Mathew Heim, Tanfield Chambers, is also Senior Adviser to 4iP Council. Dr. Igor Nikolic is Assistant Professor at Tilburg University. This paper was drafted with the support of 4iP Council and expands on a scoping paper submitted to the European Commission on Sept. $29^{\text {th }}, 2018$ by 4 iP Council entitled A FRAND regime for dominant digital platforms? Contribution by 4iP Council to the European Commission's workshop on Shaping Competition Policy in the Era of Digitisation. The opinions expressed in this paper are those of the authors and do not necessarily represent the opinions of 4iPCouncil nor its members. can grow - and have grown - to significant scale and their market position, exacerbated by network effects, may soon appear unassailable. The impact of dominant digital platforms can also be felt on adjacent and downstream markets, whether as a result of multi-sided markets or possible leveraging. Yet applying traditional competition law doctrines to evolving technology markets raises a host of challenges for regulators.

2 In addition to more "classic" competition concerns, new issues, not traditionally within the competition policy space, are increasingly being voiced. These issues include the following: the importance of data as the fuel of the new economy; privacy and data protection; media plurality; and democratic health or the like. 
3 At the same time, the European Commission is also considering how to build a strong European policy that would leverage the data economy, artificial intelligence, the internet of things, blockchain and other key enabling elements to Europe's digital future, ${ }^{2}$ in which competition enforcement may play a secondary role. ${ }^{3}$ Classic competition enforcement is therefore but one of the tools available to policymakers in addressing some of the issues raised by dominant digital platforms.

4 This paper explores how European policy and legislation has addressed issues of access to critical goods or services in the past, in order to provide inspiration to the ongoing debate.

\section{B. Summary}

5 This paper reviews some of the practices of the European Union (EU) institutions when seeking to ensure access to critical infrastructure or inputs, whether through enforcement or regulation, and which can serve as inspiration to the European Commission in considering how to address dominant digital platforms. We focus on one particular access regime, that can be set up either ex ante or applied as an ex post remedial solution in order to enable fair-trading conditions between digital platforms and users. Ensuring trading between a dominant digital platform and others on Fair, Reasonable and Non-Discriminatory (FRAND) basis might be a very useful option, given that FRAND is a commonplace, flexible and proven mechanism that is relied on in both commercial agreements and regulation.

6 This paper starts from the position that dominant digital platforms will likely face regulation in one form or another. ${ }^{4}$ The aim of the paper is to show

2 See European Commission, Building a European Data Economy (Communication) COM (2017) 9 final; European Commission, Towards a common European data space (Communication) COM (2018) 232 final; European Commission, Proposal for a Regulation of the European Parliament and of the Council on promoting fairness and transparency for business users of online intermediation services (Communication) COM (2018) 238 final 2018/0112 (COD); European Commission, Artificial Intelligence for Europe (Communication) COM(2018) 237 final. See also Begona Otero, Evaluating the EC Private Data Sharing Principles: Setting a Mantra for Artificial Intelligence Nirvana?, 4iP Council, December 2018. Available at: <https:// www.4ipcouncil.com/application/files/8315/4394/1658/ Evaluating_the_EC_Private_Data_Sharing_Principles.pdf>.

3 For example, in its Proposal for an online intermediation services Regulation the European Commission acknowledges a lacuna in addressing "unilateral potentially harmful trading practices" by digital platforms that are not necessarily competition law infringements and which European competition law may therefore not address.

4 As Cremer put it, "Given their societal importance, there will be strong regulations of platforms". See Jacques that, on that assumption, the FRAND access regime has shown itself to be a flexible tool for managing platforms and could be applied as a safe harbour or a regulatory solution to dominant digital platforms.

7 The paper is structured as follows. We first review competition law issues surrounding the conduct of dominant digital platforms. Second, we look at the applicability of FRAND access principles in relevant competition cases. We then review the FRAND access concept applied in some key EU legislation governing standardisation; chemicals; electronic communications framework; public sector information; research framework; vehicles emissions, payment services; credit rating agencies and benchmark regulations. This is not a forensic review of European FRAND-based legislation but seeks instead to capture the principal examples thereof. Finally, we summarise some of the essential elements of the European FRAND regime before concluding.

\section{Issues surrounding the application of competition law in regulating the conduct of dominant digital platforms}

8 How to assess the effects of dominant digital platforms on competition and what, if anything, should be done is subject to an ongoing debate in the literature and policy circles. ${ }^{5}$ The fundamental issue is that dominant digital platforms effectively create an ecosystem lock-in. This may be either because competition is often "for" the market not "on" the market, or because the platform functions as de facto gatekeeper to an ecosystem, pulling in service or content suppliers, intermediaries, customers or consumers. ${ }^{6}$

Cremer presentation at ICLE/University of Leeds Annual Competition Law Conference 25 October 2018, Washington DC.

5 For example, the US Federal Trade Commission is currently looking at "the identification and measurement of market power and entry barriers, and the evaluation of collusive, exclusionary, or predatory conduct or conduct that violates the consumer protection statutes enforced by the FTC, in markets featuring "platform" businesses." See <https:// www.ftc.gov/news-events/press-releases/2018/06/ftcannounces-hearings-competition-consumer-protection21st>. See also the inquiry by the Australian Competition and Consumer Commission into the market power of digital platforms e.g. <https://www.accc.gov.au/focus-areas/ inquiries/digital-platforms-inquiry>. See also Khan, Lina, Amazon's Antitrust Paradox (January 31, 2017). Yale Law Journal, Vol. 126, 2017.

6 See US Senator Mark Werner's observation regard: “certain technologies serve as critical, enabling inputs to wider technology ecosystems, such that control over them can be leveraged by a dominant provider to extract unfair terms 
9 Where the platform's role is central to the ecosystem and certain players are locked-in, the market position of a platform may be practically impossible to challenge. Nevertheless the question remains whether new players or new ecosystems can create effective competitive constraints on the platform or whether some competitive pressure needs to be maintained through regulation, in order to ensure that actors within the ecosystem have access to critical elements of the platform, especially to enable continued competition in secondary or associated markets.

10 Regulators around the world face a challenge to create a satisfactory framework to ensure fair access of consumers and users to digital platforms supporting an environment for innovation and competition in dynamic markets. After many years of exploration, including some enforcement decisions, there is no consensus on some critical issues, ranging from simple taxonomy, to the more complex issue of market definition; tipping points that connote-market power; the extent dominant platforms can distort competition; the welfare costs of intervention; or the difficulty of designing effective ex post remedies. ${ }^{7}$ Enforcers continue to face difficulties in fitting classic competition analysis to this paradigm, yet as noted by Coyle “... without a greater degree of consensus about how to analyze competition in digital platform markets, including methodologies for empirical assessment, it will be impossible for the relevant authorities or courts to do anything other than feel their way along on a case by case basis".

11 Is the existing competition assessment toolkit sufficient to catch abusive "dominant" digital platforms or does it need to be expanded? Tirole notes "With rapidly changing technologies and globalization, traditional regulatory tools have become less effective, causing competition policy to lag" and "Policymakers and regulators around the world must face the fact that the reasoning behind traditional competition measures is no longer valid".

from, or otherwise disadvantage, third parties". See White Paper, Potential Policy Proposals for Regulation of Social Media Technology Firms (2018) available at: <https://regmedia. co.uk/2018/07/30/warner_social_media_proposal.pdf>.

7 See Melamed, Doug and Petit, Nicolas, The Misguided Assault on the Consumer Welfare Standard in the Age of Platform Markets (October 30,2018) Available at SSRN: <https://ssrn. com/abstract=3248140> or <http://dx.doi.org/10.2139/ ssrn.3248140> (reviewing the debate).

8 See Diane Coyle, Practical competition policy implications of digital platforms, Bennett Institute for Public Policy working paper no: 01/2018, March 2018. At <https:// www.bennettinstitute.cam.ac.uk/media/uploads/files/ Practical_competition_policy_tools_for_digital_platforms. pdf>.

9 See Jean Tirole, Regulating the disrupters, Livemint, 1 January 2019 at <https://www.livemint.com/Technology/
Coyle suggests that rather than focusing on prices and consumer switching behaviour or traditional market definition, antitrust authorities should favour a wider assessment of the platform's market ecosystem, focusing "on the scope for disruptive technological innovation and the dynamic consumer benefits of investment". ${ }^{10}$ Yet others question calls for a broadening of the consumer welfare standard. As Melamed \& Petit note: "Unless critics intend to make antitrust law a general tool for attacking all sorts of inequalities in size, power and wealth unrelated to market competition, they will not be able to improve antitrust law by abandoning the [consumer welfare] standard in platform markets in particular and across industries in general." ${ }^{11}$ To borrow a phrase from Fox, this debate is nothing less than a battle for the soul of competition law. ${ }^{12}$

12 Another aspect is whether the competition law system is able to play a part in addressing societal concerns created by supra-dominant platforms which, through their sheer size, have such a seismic impact on whole economies and even democracies. should the "bigness" of the handful of "mega" platforms even be a concern of competition law? should the standard of consumer welfare be expanded beyond the "classic" consumer to capture, for example, the individual as a data subject, as an employee or even a voter? Should data (or subset thereof) be considered an essential input, or should some dominant platforms be considered an essential facility?

13 If current competition law approaches contain inadequacies in addressing problems associated with dominant digital platforms, some suggest that legislation could be used to define new thresholds (e.g. user base, size, lock in) above which "certain core functions/platforms/apps would constitute 'essential facilities', requiring a platform to provide third party access on fair, reasonable and nondiscriminatory (FRAND) terms and preventing platforms from engaging in self-dealing or preferential conduct". ${ }^{13}$ In addition, legislation or regulation could ensure access to critical technology by requiring that dominant platforms maintain

XsgWUgy9tR4uaoME7xtITI/Regulating-the-disruptersJean-Tirole.html>.

10 Coyle (2018), p 12. See footnote 9. See also Bamberger, Kenneth A. and Lobel, Orly, Platform Market Power (November 20, 2017). 32 Berkeley Technology Law Journal 1051 (2017); San Diego Legal Studies Paper No. 17-311; UC Berkeley Public Law Research Paper. Available at SSRN: <https:// ssrn.com/abstract=3074717>.

11 Melamed \& Petit (2018), p 42. See footnote 7.

12 Eleanor M. Fox, The Battle for the Soul of Antitrust, 75 Calif. L. Rev. 917 (1987).

13 Senator Mark Werner, White Paper, Potential Policy Proposals for Regulation of Social Media Technology Firms (2018). See Footnote 7. 
Application Programming Interfaces (APIs) for third party access, thus achieving interoperability, under FRAND terms. However, even some who argue that the consumer welfare standard should be broaden acknowledge that competition law should not be used to make every successful platform a utility. ${ }^{14}$

14 It should be unnecessary to consider the "essential facilities" doctrines broadly. In elaborating coherent rules for emerging platforms that may reach a tipping point (and be conferred with the special responsibility that comes with market power), ex ante "remedies" can be devised to ensure that lock in does not occur. The issue only really arises when considering what should be done with existing "mega-platforms" and whether, after recognising a problem, a remedy can be fashioned that addresses various tensions of proportionality, effectiveness, as well as practicality, that are rooted in commercial reality.

15 This paper therefore explores existing practices relating to FRAND access in European law and policy as a possible practical framework to address situations where digital platforms are either found to be dominant or where platforms may wish, ex ante, to adopt a reasonable and pragmatic solution, in order to avoid allegations of market power or its abuse - and therefore forestall regulatory scrutiny.

16 The next sections will describe and analyse the applicability of FRAND access framework in EU competition law and legislation.

\section{FRAND in the Context of Competition Law \& Policy}

\section{Competition Policy and FRAND}

17 The concept of "fair, reasonable and nondiscriminatory" access is increasingly used by competition authorities as a "good faith" notion, applied as a competition law remedy to ensure the supply of a particular product or the access to specific infrastructure. ${ }^{15}$ In particular, FRAND access

14 Tim Wu, Taking Innovation Seriously: Antitrust Enforcement if Innovation Mattered Most, (2012), Antitrust Law Journal No. 2.

15 For instance, in the context of the Microsoft case the European Commission determined that Microsoft's operating system APIs was an essential input that Microsoft could not abusively refuse to license and required a FRANDbased access remedy. See also Case T-201/04, Microsoft v. Commission, 2007 E.C.R. II-3601, para 193. See also paras. 808 et seq. and para. 1231 and 1261 . Petit notes that “... the 2018 Google Android case is a repeat of the 2004 Microsoft case, suggesting consistent support to the idea of keeping technology platforms open". See Petit, Nicolas, Competition Cases Involving Platforms: Lessons from remedies in competition cases have been used in both abuse of dominance and merger review cases and across a range of sectors.

18 From a theoretical perspective, it could be argued that Article 102 TFEU already embraces a FRAND-based notion; it eschews excessive prices ${ }^{16}$ while promoting access and non-discrimination obligations, ${ }^{17}$ as required under the "special responsibility" of dominant firms..$^{18}$ FRAND-based access remedies have been used in Article 102 TFEU compulsory licensing cases, ${ }^{19}$ yet this does not mean that a compulsory licensing remedy should be broadly imposed on dominant digital platforms (unless exceptional circumstances can be established). We will see that European competition law already has some experience in applying FRAND-based access remedies, where the European Commission has sought to ensure market access but did not want to engage in setting precise prices or terms. ${ }^{20}$

Europe (October 17, 2018). Available at SSRN: <https://ssrn. com/abstract=3285277>), p.5.

16 A non-FRAND rate under the terms of contract law or as a regulatory solution cannot be automatically equated to exploitative abuse under competition law, which is of a higher threshold. See for example Case M.7995 Deutsche Borse/London Stock Exchange Group, para 106.

17 Article 102(c) TFEU. See also Melamed \& Petit (2018). See footnote 7.

18 On special responsibilities of dominant firms see Case 322/81 Nederlandsche Banden Industrie Michelin (Michelin I) v Commission [1983] ECR 3461, paragraph 57; Case T-83/91 Tetra Pak v Commission (Tetra Pak II) [1993] ECR II-755, paragraph 114; Case T-111/96 ITT Promedia v Commission [1998] ECR II-2937, paragraph 139; Case T-228/97 Irish Sugar v Commission [1999] ECR II-2969, paragraph 112; and Case T-203/01 Michelin v Commission (Michelin II) [2003] ECR II-4071, paragraph 97. CaseC-209/10 Post Danmark A/S v Konkurrencerådet, EU:C:2012:172, paragraphs 21-23.

19 See e.g. Joined cases C-241/91 P and C-242/91 P, RTE \& ITP $v$ Commission [1995] ECR I-743, Case 418/01, IMS Health $v$ NDC Health, [2004] ECR I-5039 and Case T-201/04, Microsoft Corp. $v$ Commission, [2007] ECR II-3601. See for example European Commission decision of 21 December 1988 in case IV/31851 Magill TV Guide, para 27: "Accordingly the only remedy possible in the present case is to require ITP, BBC and RTE to supply each other and third parties on request and on a non-discriminatory basis with their individual advance weekly programme listings and to permit reproduction of those listings by such parties .... If they choose to supply and permit reproduction of the listings by means of licenses, any royalties requested by ITP, BBC and RTE should be reasonable".

20 FRAND competition remedies, like all regulatory measures, should also satisfy the principle of proportionality (See for example Case C-180/96 United Kingdom v Commission, I2265, para 96). Given that the FRAND regime is based on fairness and reasonableness, that it adopts commercial practices and imposes obligations of good faith on all parties, it is likely that the FRAND regime is limited to what is needed to address concerns, is the least onerous measure, and is proportionate to the aim envisaged. See also Cyril Ritter, How Far Can the Commission Go When Imposing Remedies for Antitrust Infringements?, Journal of European Competition Law \& Practice, 2016. 
19 There have now been a number of merger review cases in Europe where parties have agreed to adopt a FRAND-based behavioural remedy to ensure that existing market players or new entrants are placed in a position where they can effectively compete with the merged company. ${ }^{21}$ The FRAND access remedy has been qualified as an "appropriate benchmark" 22 in a merger review and applied by different jurisdictions across diverse sectors, such as medical equipment, television broadcasting, music streaming licensing, payment processing, gas networks, flight search, missile systems, technology platforms and herbicides. ${ }^{23}$ Lessons can therefore be drawn from cases where FRAND-based remedies have been accepted to address input foreclosure concerns by ensuring access to critical "must have" inputs (considered essential for third parties to compete effectively with the merged entity), including ensuring that customers are supplied on the same or similar terms to the merged entity's own business.

20 European competition authorities have specifically addressed the issue of ensuring interoperability between device interfaces or communications protocols, associated software and data management systems. In Newscorp/Telepiu access to platform APIs was ensured on FRAND terms, so far as was necessary to allow downstream pay-TV providers to develop interactive services compatible with

21 The European Commission is by no means alone in its reliance on the FRAND principle in merger remedies. Competition authorities around the world are increasingly accepting FRAND-based remedies in a merger context including the US Department of Justice review of Google/ ITA (2011), the US FTC review of Northrop Grumman/Orbital (2018), the decision of the Competition Commission of India and of MOFCOM of China in Bayer/Monsanto (2018), the decision of the South African Competition Tribunal in Dow/ DuPont (2017) and the Japan FTC in ASML/Cymer (2012).

22 See Liberty Global/De Vijver Media, COMP/M.7194 (2015), para. 655. "...[T]he Commission considers that the reference to 'fair, reasonable and non-discriminatory terms' is the most appropriate benchmark to for the terms to which various types of TV distributors will be entitled under the commitments". See also paras. 624-5, and 672 .

23 See cases referred to in footnotes $22,23,25-27$. See also PRSfM/STIM/GEMA COMP/M.6800. where the joint venture partners agreed that the joint venture would offer key copyright administration services to other collecting societies on FRAND terms, when compared to the terms offered to the individual members of the joint venture. Also, access to physical infrastructure have been assessed as an essential input in: Hellenic Petroleum/British Petroleum Hellas SA, HCC 465/VI /2009. The Hellenic Competition Commission (HCC) imposed a FRAND commitment on Hellenic Petroleum (ELPE) whereby ELPE would grant access to third parties (wholesalers) to its storage facilities/ depots in Crete under FRAND terms. See also Contribution of Greece to the Roundtable on Remedies in Merger Cases held by the OECD's Competition Committee (Working Party No.3 on Cooperation and Enforcement), June 2011. DAF COMP(2013)11, 30 July 2012. the decoders and software used by the combined entity's platform's customers. ${ }^{24}$ In Siemens/ Drägerwerk, royalty free FRAND commitments were given to ensure continued interoperability between medical equipment platforms and hospital data management systems, including making available and maintaining all existing and future interfaces and communications protocols. ${ }^{25}$ In Worldline/Equens the merging parties agreed to license on FRAND terms to payment network service providers (NSPs) within Germany key card and payment processing software, as well as the source code for the Poseidon software and the ZVT protocol, on which most German point of sale terminals run. ${ }^{26}$

21 It is worth noting that in Worldline/Equens, additional "flanking" commitments were offered to ensure that the FRAND remedy was effective. These include effectively capping software maintenance fees for 10 years; ensuring additional costs (e.g. maintenance services were also under FRAND terms); that NSPs' access would be prioritised over Worldline's PaySquare in case of shortage; including new modules and upgrades at no additional cost; that NSPs would have access to Poseidon source code for internal business use, in return for a oneoff price-regulated fee; to place governance of the ZVT protocol with an external, independent notfor-profit, entity that would represent all market participants; that the Licensing Trustee would have access to all of Worldline licenses, contracts, pricing and invoicing conditions enabling it to effectively review the commitments, and that NSPs could seek more favourable terms if the Licensing Trustee considered PaySquare had advantageous terms; and set up a fast-track dispute resolution mechanism. Finally, as a compliance tool, a material breach of the remedies would result in NSPs having access to the source code free of charge. ${ }^{27}$

22 The Newscorp/Telepiu remedy is also worth further comment. During the Commission's investigation, third parties expressed concerns that the applicable European regulatory framework, which required those operators to offer access of digital television services on a FRAND basis to all broadcasters, ${ }^{28}$ might not be sufficient to constrain likely foreclosure by Newscorp in the Italian pay-TV market. ${ }^{29}$ The

24 Newscorp/Telepiu, COMP/M.2876 (2004).

25 Siemens/Drägerwerk, COMP/M.2861 (2013), para 154.

26 Worldline/Equens, COMP/M.7873 (2016). See also <http:// europa.eu/rapid/press-release_IP-16-1462_en.htm>.

27 See also Paul McGeown' EU Merger Control 2016: Behavioral Remedies, No Longer Taboo, The Antitrust Report, LexisNexis, May 2017.

28 Notably the implementation of then Directive 95/47/EC, the Directive on Television Transmission Standards, and Directive 2002/19/EC, the old 'Access Directive' (see Section V.(f) below).

29 Newscorp/Telepiu, para 121 identifying specific concerns 
European Commission found that cooperation with and by Newcorp or its subsidiary, NDS, was critical to enter the Italian pay-TV market. Most interestingly, the European Commission found ${ }^{30}$ that given the technical difficulties for pay-TV operators both using a different CAS to NDS or implementing Simulcrypt obligations within a short period of time, it created a complete dependence on the combined entity from the technological viewpoint. ${ }^{31}$ Newscorp's control of the technical platform would give it the possibility and the incentive to set the standard for the accepted level of "intra-platform" competition. The European Commission therefore imposed measures to effectively compel Newscorp to comply with the existing FRAND rules found within the legislative framework. In that context, while a monitoring trustee was appointed to ensure compliance with the remedies, disputes related to the licensing terms fall to be adjudicated to the Italian Communications Authority, the national regulatory authority responsible for safeguarding the implementation of the regulatory framework. Newscorp/Telepiu therefore agreed to allow access to the API so far as necessary to develop interactive services compatible with the decoders used by the Combined Platform's customers. ${ }^{32}$

23 In sum, the FRAND regime has now been applied by competition authorities in Europe (and indeed further afield) to ensure access to products and services across a range of sectors. FRAND access commitments have proved particularly useful and are the least intrusive remedies, where there is no adequate regulatory framework in place that addresses underlying competitive concerns. ${ }^{33}$

24 Competition law can therefore continue to ensure intra- and inter-platform competition by promoting access to critical inputs using a tried-andtested regime that ensures a balance of interests,

regarding technical services for pay-TV, and in particular conditional access systems being the likelihood that the new entity grant access to the NDS technology for CAS to potential new entrants under unfair terms and conditions; and that the new entity obstruct the entry of alternative pay-TV platforms with a different CAS system from that of NDS, leading to a virtual monopoly, in view of the fact that NDS would become the only CAS used in Italy.

30 Newscorp/Telepiu, para 140.

31 "A number of respondents in the market investigation have gone as far as considering NDS technology as a sort of 'essential facility' for the Italian pay-TV market". See Newscorp/Telepiu, para 124.

32 Newscorp/Telepiu Commitments, Part II, para 11.5.

33 FRAND remedies also address regulatory efficiency concerns as they are also self-policing, as a FRAND regime grants a clear cause of action before the courts to third parties harmed by exclusion or non-FRAND terms, as well as possible ex post regulatory actions under Article 102 (and what that would imply for remedies for findings of exclusion). guaranteeing equality of arms in negotiations, minimising impact of regulatory intervention, and basing remedies on existing sector practices. Indeed, in setting out some lessons to be drawn from European competition cases involving platforms, Petit observes that while EU technology policy is premised on ex ante regulation, antitrust enforcement appears to effectively act as a "fact finding exercise or as a regulatory kick starter seconded by regulatory propositions, notably as relates to online platform regulation." ${ }^{34}$

25 Competition law policy is an important complement to broader European policy measures, but competition policy should not be primarily driven through cases: such an approach has significant flaws. First, imposing FRAND access as a merger remedy is opportunistic and dependent upon having a notifiable merger to begin with. If there is no relevant merger review where a FRAND access regime can be considered, alternative instruments should be considered to provide guidance to undertakings. In any event, FRAND access remedies would be merger-specific and could not necessarily be applied as a universal solution to dominant digital platforms across similar markets. The same can be said for other competition enforcement measures. Second, in non-merger cases, substantive competition law investigations are inherently slow. They typically last for several years during which market developments may often render any remedy too late to address pressing competitive concerns. In addition, enforcement cases are also fact-specific and companies under investigation should be confident that their case will not be "hijacked" for policy-making purposes. Finally, if cases end up in commitment decisions, any FRAND access remedy may provide little precedential value for other companies. Consequently, competition law remedies should be complemented by broader policy measures. There is therefore something to be said for a more structured competition approach to FRAND, especially given the jurisprudence already developed by the European Commission.

26 Competition law and national competition authorities may have a role to play in providing more structural guidance to companies. As Tirole notes, "rapidly changing technologies and globalization, traditional regulatory tools have become less effective, causing competition policy to lag", which requires more agile policies to be developed including "soft law" instruments. ${ }^{35}$ From a competition perspective, formal guidance could well be useful where platforms risk creating silos

$34 \quad$ See Petit (2018). See footnote 15.

35 See Jean Tirole, Regulating the disrupters, Livemint, 1 January 2019, at <https://www.livemint.com/Technology/ XsgWUgy9tR4uaoME7xtITI/Regulating-the-disruptersJean-Tirole.html>. 
or proprietary ecosystems, locking out alternative players. A good example relates to the connected car, which will generate data of driver and passenger behaviour and experiences, automotive diagnostics, driving and road conditions that will feed into services related to driving and linked services. To what extent should the platforms controlling the accessing of this data seek to avoid walledgardens or silos? While platforms should assess the risk themselves, guidance from the European Commission would be welcome if only to delineate scope of action. ${ }^{36}$ There is sufficient jurisprudence in European law for the European Commission to provide guidelines on FRAND access regimes in relation to dominant digital platforms. This would not only help to ensure that binding access regimes are adopted ex ante, but could provide guidance to companies considering offering commitments to address competition concerns under Article 9 of Regulation 1/2003.

\section{Competition Policy and "Standardisation FRAND}

27 Patents essential for practicing a technology standard (Standard Essential Patents or SEPs) have recently been in focus, regarding the applicability of the EU's competition law to access to these patents. Technical standards can broadly be categorised as collaborative, when they are developed within the framework of Standard-Development Organisations (SDO), or de facto, when they are developed outside of any institutional framework of SDOs and achieve broad market acceptance to effectively become a standard on the market. Competition law in Europe has taken a FRAND-based approach to essential patents related to both collaborative and de facto standards.

28 FRAND licensing commitments, in the context of technical standards, are intended to ensure widespread access to a standard for implementers while, at the same time, providing adequate rewards and incentives to technology developers. Although FRAND commitments are voluntarily given by SEP owners to SDOs, the European Commission views that the existence of a FRAND policy will place the SDOs, and their contributing members, within the safe harbour of Article 101 TFEU. ${ }^{37}$ Complying with

36 See Wolfgang Kerber, Data Governance in Connected Cars: The Problem of Access to In-Vehicle Data, 9 (2018) JIPITEC 310 para 1.

37 European Commission Guidelines on the applicability of Article 101 of the Treaty on the Functioning of the European Union to horizontal co-operation agreements, (Communication) OJ C11, 14 January 2011. See para 279. In addition, the European Commission's Technology Transfer Guidelines go somewhat further, suggesting that FRAND commitments should be the FRAND safe harbour means that there is, in principle, no need to undertake the often-complex task of assessing market power or dominance of SEP owners.

29 A FRAND commitment may also have an important impact on the availability of injunctive relief which, if granted by a court, may deny the infringer access to that standard. In the Huawei $v$ ZTE, ${ }^{38}$ the Court of Justice of the EU (CJEU) considered whether a SEP owner found to be dominant had abused that dominant position where it sought an injunction for the infringement of its SEP, to which a FRAND commitment had been made. The Court held, amongst other things, that a competition law defence could be raised by an infringer of an SEP against a request for an injunction, where a dominant SEP holder had not followed certain steps, including making a FRAND offer. ${ }^{39}$ Following those steps creates a safe harbour for the SEP holder when requesting an injunction. However, the Court also set out certain steps that the infringer has to follow if they were to be able to avail themselves of such a defence. As a result, the Court set out a negotiating process that, where followed, should lead to a FRAND outcome. What Huawei v ZTE shows is that, in the event of a dispute, where both parties follow the steps required of them, access on a FRAND-basis is ensured and third parties are not unduly excluded on the basis of proprietary rights. It also shows, at a high level, that the Court built its decision around the FRAND commitment.

30 In the context of de facto standards, the German Bundesgerichtshof permitted a competition law defence to be raised where a patent infringer was not able to get a FRAND-like licence to a patent in a de facto standard, even where a FRAND commitment had not been made expressly or required by regulation. ${ }^{40}$

included in patent pools' self-assessment, whether or not these pools were licensing SEPs.

38 See Huawei Technologies Co. Ltd $v$ ZTE Corp., ZTE Deutschland GmbH, Case C170/13, 16 July 2015, available at <http://curia.europa.eu/juris/document/document. jsf?docid $=165911 \&$ doclang $=$ en $>$.

39 See Huawei $v$ ZTE para 54 of the CJEU ruling: "It follows that, having regard to the legitimate expectations created, the abusive nature of such a refusal may, in principle, be raised in defence to actions for a prohibitory injunction or for the recall of products. However, under Article 102 TFEU, the proprietor of the patent is obliged only to grant a licence on FRAND terms."

40 On the facts before it, the court clarified that the compulsory licence defence against the request for injunctive relief was only possible when the alleged infringer has made an offer to the patent proprietor that the patent proprietor could not reject without being anticompetitive, and behaves as if the patent proprietor had already accepted his offer. See Orange Book Standard, KZR 39/06, (BundesgerichtshofBGH, May 6, 2009). 
31 In conclusion, EU competition law promotes licensing of SEPs on FRAND terms both by providing a safe harbour under Article 101 TFEU to SDOs, which have policies requiring FRAND commitments from their members and by ensuring a balanced path, based on good faith behaviour, to resolving SEP licensing disputes that would result in a FRAND agreement.

\section{E. European Legislation, Regulation, Policies and FRAND}

32 The notion of access on FRAND terms has also been used by the European legislature well beyond competition law. In pursuing public policy objectives, FRAND-based access has been applied across different sectors as a means of ensuring that critical inputs are made available for market participants. This creates a further useful source of European authority for the contention that the FRAND regimes is a suitable access remedy.

\section{FRAND in the context of Standardisation Regulation}

33 As mentioned, FRAND is a widely used notion in the context of licensing patents that are essential to practicing a technology standard. The FRAND commitment is voluntarily given by a technology contributor to an SDO. At its highest level, the FRAND commitment exists to ensure access to patented essential technologies on terms that are fair and reasonable for both licensor and licensee in order to, firstly, guarantee the uptake of new technologies and its wide diffusion, and secondly, encouraging valuable technology contributions to be made to standardisation efforts (thus encouraging further incentives to innovate in future standardisation). ${ }^{41}$ The FRAND regime therefore seeks to balance competing interests of different players and making standardisation an attractive enterprise for all kinds of business models. Depending on the jurisdiction, a FRAND commitment is usually an enforceable defence under contract law or other principles such as quasi-contract, estoppel and in some instances antitrust law. ${ }^{42}$

41 See the European Commission, Setting out the EU approach to Standard Essential Patent (Communication), COM(2017) 712 final, 29 November 2017. Moreover, SDOs typically follow certain principles established by the World Trade Organisation that ensure that an SDO is business neutral. See more on the principles, such as openness, consensus based, transparency, and impartiality at Fredrik Nilsson, Appropriate base to determine a fair return on investment: A legal and economic perspective on FRAND, GRUR Int. 2017, 1017.

42 National SEP litigation tends to focus mainly on noncompetition elements, see for example Huawei v. Unwired Planet, [2017] EWHC711(Pat) and the Court of Appeal review
34 Standards are a typical example of the creation of an innovation platform, done openly and transparently. As Tsilikas noted: "Collaborative standardization under the auspices of [SDOs] has, thus far, a remarkable record of breakthrough technological achievements, high-quality, cutting-edge standards, vibrant follow-on innovation in the implementation of standards and open, competitive upstream and downstream markets. Standardization in wireless telecommunications is driven by an inexorable dynamic: more innovative standards, services and products increase consumer demand and increased consumer demand calls for more investment in $\mathrm{R} \& \mathrm{D}$, more innovation and better-performing interoperability standards." ${ }^{43}$

35 Core to that openness and transparency is the access to essential technology through the FRAND regime. The FRAND regime has empirically led to hugely successful results, ensuring both broad access to and wide dissemination of advanced technologies. ${ }^{44}$

36 What the precise rights and obligations are that the FRAND regime creates depends on the intention of the parties (usually set out in the SDO's IPR policy) and the specificities or usual practices of the particular industry. ${ }^{45}$ The flexibility of the FRAND commitment has led it to be broadly adopted by SDOs across the board, notably the formal EU standardisation

of that decision [2018] EWCA Civ 2344 or the repository of post-Huawei $v$ ZTE national case law at <https:// caselaw.4ipcouncil.com/>.

43 Tsilikas, Haris, Collaborative Standardization and Disruptive Innovation: The Case of Wireless Telecommunication Standards (May 17, 2016). Max Planck Institute for Innovation \& Competition Research Paper No. 16-06. Available at SSRN: $<$ https://ssrn.com/abstract=2783372>.

44 For example, between 2005 and 2013, the average mobile subscriber cost per megabyte decreased 99 percent, mobile network infrastructure costs were reduced by 95 percent, and $4 \mathrm{G}$ networks were able to transfer data 12,000 times faster than $2 \mathrm{G}$ networks. See Boston Consulting Group, The Mobile Revolution, January 2015. According to GSMA by $20255 \mathrm{G}$ networks are likely to cover one-third of the world's population. See more at <https://www.gsma. com/futurenetworks/technology/understanding-5g/5ginnovation/>.

45 There are international SDOs that do not use the exact expression "FRAND" in their IPR policies yet achieve the same result. SAE International, for example, is a US-based organisation that, inter alia, develops voluntary consensusled standards covering aspects of design, construction, performance, durability, and promotes for commercial vehicle and automotive engineering. Within the context of patents in SAE's IPR policy, patents and patent applications can be included provided that SAE receive either a general disclaimer from the patent holder that they will not enforce any of their IP against implementers or that they state that "a license will be made available to all applicants without compensation or under reasonable rates, with reasonable terms and conditions that are demonstrably free of any unfair discrimination." See <https://www.sae.org/binaries/ content/assets/cm/content/about/sae-ip-policy.pdf>. 
bodies, ETSI and CEN/CENELEC, as well as numerous informal standards organisations. ${ }^{46}$ As a result, this industry-led solution has been enshrined in the European Standardisation Regulation, ${ }^{47}$ and broadly promoted in European standardisation policy, ${ }^{48}$ as part of the regulatory framework around standards development and dissemination.

37 Indeed, the European Commission's recent FinTech Action Plan notes that that "An EU-wide FinTech market will not reach its full potential without the development of open standards that increase competition, enhance interoperability and simplify the exchange of and access to data between market players". ${ }^{49}$ Implementing such interoperability can be done through ad hoc interfaces, which raises efficiency and competition issues, or interoperability standards for the whole market on the basis of the principles within the European Standardisation Regulation which, as noted above, seeks to ensure effective access through FRAND terms.

38 As a final note, the negotiation framework devised by the CJEU in Huawei $v$ ZTE could provide inspiration for other non-SDO situations. In Huawei $v$ ZTE the CJEU required the holder of the essential input to set out clearly what the input consisted of as well as its price, where upon the customer, having all the elements necessary to take a decision, has to accept to negotiate and diligently agree to the offer or make a reasonable counter offer. ${ }^{50}$ Such a

46 Tim Pohlman, Knut Blind, Landscaping Study on Standard Essential Patents (2016) p. 36 (finding that 68\% of all declared SEPs are licensed under FRAND terms, while the remaining $32 \%$ do not specify licensing conditions); Justus Baron \& Daniel Spulber Technology Standards and Standard Setting Organisations: Introduction to the Searle Center Database (2018) 27 Journal of Economics \& Management Strategy 462 (studying IPR policies of $37 \mathrm{SSO}$ and find that 32 SSOs allow for FRAND licensing, with the remaining 5 SSOs require royalty-free licensing)

47 See the European Standardisation Regulation No 1025/2012, 25 October 2012, which seeks to create "an effective and efficient standardisation system which provides a flexible and transparent platform for consensus building between all participants" and requires that for technical specifications to fall under the Regulation they be covered by the FRAND regime, reflecting WTO norms.

48 See e.g. the European Commission, Intellectual Property Rights and Standardization (COM(92) 445 final), 27 October 1992; or the European Commission, Digitising European Industry: Reaping the full benefits of the Digital Single Market, (Communication), $\operatorname{COM}(2016) 180$ final; or European Commission, ICT Standardisation Priorities for the Digital Single Market (Communication) COM(2016) 176 final of 19 April 2016; or the European Commission, Setting out the EU approach to Standard Essential Patents (Communication) COM(2017) 712 final, 29 November 2017.

49 European Commission, FinTech Action plan: For a more competitive and innovative European financial sector (Communication), Brussels, 8.3.2018 COM(2018) 109 final.

50 Claudia Tapia and Spyros Makris, Negotiating SEP licenses in Europe after Huawei $v$ ZTE: guidance from national process is attractive as a policy solution, but it has to be acknowledged that the system was devised in the event of an inability by the parties to reach agreement and on the basis that one party had already committed to allow access to some of its technologies on FRAND terms. It cannot be used as a procedural straight jacket, as parties could well reach agreement outside of such a process. ${ }^{51}$

\section{The Regulation for the Registration, Evaluation, Authorisation and Restriction of Chemicals}

39 The Regulation for the Registration, Evaluation, Authorisation and Restriction of Chemicals (REACH $)^{52}$ creates a FRAND-like access framework for sharing previously submitted reports and data between companies. In particular, it creates a framework whereby the holder of this critical information (entities that have previously registered particular chemicals) and a potential registrant "make every effort to ensure that the costs of sharing the information are determined in a fair, transparent and non-discriminatory way". ${ }^{53}$ It is notable that REACH echoes a central tenet in Huawei $v$ ZTE, where the European Court imposes obligations on both licensor and potential licensee to seek agreement in good faith. REACH also provides for rules on costsharing (notably where there is no agreement found between the parties), as well as a dispute resolution mechanism, while respecting access to courts.

40 In considering data sharing requirements, Drexl notes that REACH contains certain features "that could be used as guidance for similar legislation in other fields". ${ }^{54}$ These include: (i) the public interest

courts, Managing Intellectual Property, May 2018. Available at <https://www.4ipcouncil.com/application/ files/1315/3018/6300/21-29_article_SEPs.pdf>.

51 In Unwired Planet $v$. Huawei, the Court of Appeal found that "We have come to the firm conclusion that the CJEU was not laying down mandatory conditions at [70] of its judgment such that non-compliance will render the proceedings a breach of Article 102 TFEU..." [2018] EWCA Civ 2344, para 269.

52 Regulation (EC) No 1907/2006 of the European Parliament and of the Council of 18 December 2006 concerning the Registration, Evaluation, Authorisation and Restriction of Chemicals (REACH), establishing a European Chemicals Agency, amending Directive 1999/45/EC and repealing Council Regulation (EEC) No 793/93 and Commission Regulation (EC) No 1488/94 as well as Council Directive 76/769/EEC and Commission Directives 91/155/EEC, 93/67/ EEC, 93/105/EC and 2000/21/EC (Text with EEA relevance).

53 See REACH Article 27(3) and 30(1).

54 Josef Drexl, Designing Competitive Markets for Industrial Data Between Propertisation and Access, 8 (2017) JIPITEC 257. 
in creating the access regime; (ii) a framework of contractual negotiations favouring "a pro-market solution over direct government intervention"; 55 (iii) a concrete base for calculating compensation, relying on the cost for undertaking the relevant study; (iv) a mechanism for dispute resolution "that enables the public interest to prevail and that provides sufficient legal certainty for the parties when they assess whether it makes sense to depart from that rule". ${ }^{56}$ One particularly interesting aspect in looking to REACH as inspiration for FRAND-based access regimes is that the public interest is broader than ones that traditionally have resulted in compulsory licensing regimes.

41 Further, as Drexl notes, the REACH framework relies on bilateral commercial negotiations to determine the conditions for a pro-competitive solution..$^{57}$ While the REACH legislation does not engage in price-setting, which is so difficult for a legislature to get right, REACH does provide cost "metrics" in the event that no agreement can be arrived at; costs are limited to sharing the proportionate costs of information necessary to satisfy registration requirements. ${ }^{58}$ Therefore legislation can provide guideposts to the parties in the event of a dispute, but the legislation need not get engaged in creating value homogeneity. These metrics are, however, specific to the scope of REACH related to the sharing of scientific studies and data and so are generally not applicable to other sectors.

\section{European Electronic Communications Code}

42 The recently adopted European Electronic Communications Code (EECC) provides updated EU-wide telecommunication rules. ${ }^{59}$ It contains a number of provisions providing for access to and interconnection of electronic communication networks on terms that are fair, reasonable and non-

55 Ibid. Drexl (2017), at para 180, also considers that a REACHlike access regime could also be implemented in situation where there is no additional public interest, arguing that this "would make sense if it is devised as a non-mandatory procedural framework for negotiations on access to information" and considers that the negotiation framework devised by the European Court in Huawei v ZTE "could especially be applicable for cases in which the holder of information publicly commits to grant access to data on FRAND terms".

56 Ibid. Drexl (2017), para 179.

57 Ibid. Drexl (2017), para 180.

58 See also the European Chemical Agency's Guidance on Data sharing at <https://echa.europa.eu/ documents/10162/23036412/guidance_on_data_sharing_ en.pdf/545e4463-9e67-43f0-852f-35e70a8ead60>.

59 Directive (EU) 2018/1972 of 11 December 2018 establishing the European Electronics Communication Code, L 321/36. discriminatory, or similarly-phrased terms.

43 For instance, the EECC allows National Regulatory Authorities (NRAs) to require operators to interconnect their networks and make their services interoperable; ${ }^{60}$ provide access to wiring and cables facilities; ${ }^{61}$ share passive infrastructure and conclude localised roaming access agreements. ${ }^{62}$ Under all these scenarios, access and interconnection conditions must be objective, transparent, proportional and non-discriminatory. While such conditions are not further defined in the EECC and are to be further elaborated by NCAs, they substantively resemble a FRAND obligation. ${ }^{63}$

44 Moreover, in certain instances the EECC specifically allows NRAs to impose FRAND-based access obligations. For example, NRAs may require access on FRAND terms to cables and wiring beyond the first distribution point; ${ }^{64}$ access to relevant facilities in order to ensure accessibility for end-users to digital radio and television broadcasting services; ${ }^{65}$ and access to technical services enabling digitallytransmitted services to be received by viewers or listeners by means of decoders. ${ }^{66}$ Additionally, holders of IP rights needed to access products and systems should ensure that licences to manufacturers of consumer equipment are on FRAND terms. ${ }^{67}$

45 Besides the above obligations that are applicable to all operators, a specific regulatory regime applies to operators found to have "significant market power" (SMP). Namely, NRAs may impose a number of obligations on such operators, such as the obligation of transparency, requiring operators to make public their terms and conditions for interconnection

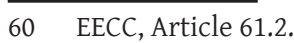

61 EECC, Article 61.3, which is applicable if it can be shown that replicating these elements would be economically inefficient or physically impracticable.

62 EECC, Article 61.4.

63 One question arises as to why these provisions apply FRANDlike concepts of "objective, transparent, proportional and non-discriminatory", were as other sections of the Directive adopt the express FRAND conditions and whether these would be materially different. No reason is immediately forthcoming, although one explanation is that the term "objective, transparent, proportional and non-discriminatory" appears to have been included in the EEC, while FRAND wording was drawn from the old Access Directive (Directive 2002/19/EC of the European Parliament and of the Council of 7 March 2002 on access to, and interconnection of, electronic communications networks and associated facilities (Access Directive), OJ L 108, 24.4.2002, notably Recital 10, Article 5.1.b and Annex I, Part I 2(b) and (c)). EECC, Article 61.3 paragraph 2.

65 EECC, Article, 61.2.d.

66 EECC, Annex II.

67 Ibid. 
and access, including information on pricing; ${ }^{68}$ the obligation of non-discrimination treatment of other similarly situated companies; ${ }^{69}$ or even the direct price control measures for interconnection and access. ${ }^{70}$ The reasons for regulating operators with SMP is to ensure ex ante competition is maintained, when traditional ex post competition law remedies may not be sufficient nor adequate to safeguard effective competition in the telecommunications market.

46 The EECC therefore contains FRAND-based access regimes to networks, infrastructure and content. It is primarily managed by NRAs, who are best placed to assess the situation on the ground, given the nature of the markets. These access regimes are imposed in order to satisfy various public policy objectives, including ensuring full end-user connectivity, resolve infrastructure bottlenecks or safeguard ex ante competition, as an adjunct to ad hoc competition enforcement. The EECC thus shows that European legislation does not shy away from mandating access to critical infrastructure in order to satisfy broader policy objectives.

47 Interestingly, the EECC also includes an obligation to provide interoperability between "interpersonal communication services", which reach a significant level of coverage and user uptake. ${ }^{71}$ This provision may arguably be used by NRAs to impose an obligation on widely used communication applications or social platforms to interoperate. ${ }^{72}$ However, such regulatory interventions may be possible only where end-to-end connectivity is endangered and only to the extent necessary to ensure connectivity between end-users. ${ }^{73}$ Nevertheless, this provision represents an evolution in providing a regulatory solution to ensuring interoperability between particular types of platforms that have a significant reach, though it may not be dominant in the competition law sense. The FRAND-based remedy is available to satisfy the broad public interest objectives found in the EECC, that include ensuring freedom of expression and information, as well as media pluralism, access to and take up of very high capacity networks and promotion of competition in the provision of electronic communications networks and associated

68 EECC, Article 69.

69 EECC, Article 70. See also Commission, 'Recommendation on Consistent Non-discrimination Obligations and Costing Methodologies to Promote Competition and Enhance the Broadband Investment Environment' 2013/466/EU (guide on interpreting the non-discrimination requirement in electronic communications legal framework).

70 EECC, Article 74.

71 EECC, Article 61.2.c.

72 See Wolfgang Kerber, Heike Schweitzer, 'Interoperability in the Digital Economy' (2017) 8 JIPITEC 39, 50-51.

73 EECC, Article 61.2.c. facilities. $^{74}$

\section{Public Sector Information Directive}

48 Directive 2003/98/EC (amended by the Directive 2013/37/EU) on re-use of public sector information, introduces FRAND-based access conditions to enable access to such information. ${ }^{75}$ Rather than referring expressly to the expression "fair, reasonable and non-discriminatory", the Directive fleshes elements to access public sector information including reasonable remuneration, non-discriminatory access and transparency, which are central elements to FRAND-based regimes.

49 In detailing the conditions for access to public sector information, the Directive sets out the following FRAND-based elements:

- Public sector bodies may charge fees for supplying and allowing access to the information. The principles governing charging under Article 6 note that "charges shall be limited to the marginal costs incurred for their reproduction, provision and dissemination" ${ }^{76}$ However, the marginal cost default does not apply where public sector bodies are required to generate revenue to cover a substantial part of their costs relating to the performance of their public tasks or, exceptionally, for documents for which the public sector body is required to generate sufficient revenue to cover a substantial part of the costs relating to their collection, production, reproduction and dissemination. Libraries, including university libraries, museums and archives are not bound by the marginal cost default, in order not to hinder their normal running. ${ }^{77}$

- Article 6 also sets out how total charges shall be calculated "according to objective, transparent and verifiable criteria to be laid down by the Member States. The total income of those

$74 \quad$ EECC, Article 3.

75 Directive 2003/98/EC of the European Parliament and of the Council of 17 November 2003 on the re-use of public sector information as amended by the Directive 2013/37/ EU of the European Parliament and of the Council of 26 June 2013, 2003L0098 (consolidated text) (PSI Directive). The PSI Directive is currently under review and a proposal for new directive has been made, see: Proposal for a Directive of the European Parliament and of the Council on the re-use of public sector information (recast) COM/2018/234 final 2018/0111 (COD).

76 See also Recital 22 of Directive 2013/37/EU. Recital 24 notes that the upper limits for charges set in the Directive are without prejudice to the right of Member States to apply lower charges or indeed no charges at all.

77 See Recital 23 of Directive 2013/37/EU. 
bodies from supplying and allowing re-use of documents over the appropriate accounting period shall not exceed the cost of collection, production, reproduction and dissemination [where relevant the preservation and rights clearance], together with a reasonable return on investment. Charges shall be calculated in line with the accounting principles applicable to the public sector bodies involved." Of note is Recital 23 that acknowledges that, when calculating a reasonable return on investment, libraries, museums and archives can consider the prices charged by the private sector for the re-use of identical or similar documents. ${ }^{78}$ Given the specific context of public sector data, the Directive can provide guide points on what elements to consider in calculating fees (which is admittedly easier than calculating fees for e.g. private sector R\&D intensive innovation).

- The requirement for non-discrimination is further specified in order to ensure free exchange of information between public sector bodies when exercising public tasks, "whilst other parties are charged for the re-use of the same documents", including differentiated charging policy for commercial and noncommercial re-use. $^{79}$

- The Directive requires that applicable conditions and the actual amount of those charges should be transparent (i.e. pre-established and public), including (on request) the calculation basis for charges and what factors should be taken into account in the calculation of charges for atypical cases. ${ }^{80}$ This approach mirrors to some degree the behavioural aspect to FRAND licensing for SEPs set out in Huawei v ZTE and the European Commission's call for transparency and predictability in SEP licensing. ${ }^{81}$

- Highlighting the importance of broad access, the Directive notes that where public sector bodies allow for re-use of documents, conditions should not unnecessarily restrict possibilities for reuse. In particular, conditions should not be used to restrict competition, ${ }^{82}$ and must be nondiscriminatory for comparable categories of reuse (rather than users), notably where re-use also occurs by the commercial activities of public sector bodies. ${ }^{83}$ Re-use is open to all potential actors and the Directive expressly prohibits the application of exclusive rights (except for the

78 Ibid.

79 See Recital 19 of the PSI Directive.

80 See Article 7 of the PSI Directive.

81 See Section V. a) above.

82 See Article 8(1) of the PSI Directive.

83 See Article 10 of the PSI Directive. digitisation of cultural resources).$^{84}$

\section{Regulation Horizon 2020}

50 The European Union's Framework Programme for Research and Innovation (Horizon 2020) is governed by Regulation $1290 / 2013,{ }^{85}$ that lays down the rules for participation and dissemination in Horizon 2020 over the years 2014-2020. In general, it can be said that the EU's “Horizon 2020" Framework Programme applies a FRAND-based model to enable access to the results of EU-funded projects, with the overarching principle for access being one of fairness and reasonableness. Article 48 of that Regulation covers access rights for exploitation and notes that, whether linked to access between project participants of the results or background information, or other, such access shall be granted under fair and reasonable conditions (subject to agreement).

51 The Commission's own Model Grant Agreements for the EU's "Horizon 2020" Framework Programme applies the model set out in the Regulation and, together with the Regulation provides an understanding of the EU's interpretation of FRAND access as a condition for accessing the results of European funded research. ${ }^{86}$ It covers the rights of participants to the agreement ("beneficiaries" of funding) to have access under fair and reasonable conditions to each other's results (relevant background input held by participants prior to their accession to the project) that are needed for exploiting their own results. ${ }^{87}$ Such access conditions apply where beneficiaries give each other access to the results needed for implementing their own tasks (or to other beneficiaries or affiliated entities). ${ }^{88}$ In addition, there are options to require (when foreseen in the work programme) access to third parties for additional access rights for interoperability under fair and reasonable or royalty free conditions. ${ }^{89}$

$84 \quad$ See Article 11 of the PSI Directive.

85 Regulation (EU) No 1290/2013 of the European Parliament and of the Council of 11 December 2013 laying down the rules for participation and dissemination in Horizon 2020 - the Framework Programme for Research and Innovation (2014-2020) and repealing Regulation (EC) No 1906/2006. OJ L347/81, 20.12.2013.

86 See the H2020 Programme Multi-Beneficiary Model Grant Agreement of October 2017 at <http://ec.europa.eu/ research/participants/data/ref/h2020/mga/sme/h2020mga-sme-2-multi_en.pdf>.

87 Ibid, Article 25 (access is restricted if the beneficiary holding the background has notified others prior to signing the Agreement that access to its background is subject to legal restrictions or limits).

88 Ibid, Article 31.

89 Ibid, Article 31.6. 
52 Article 2(1)(10) of the Regulation defines "fair and reasonable conditions" to mean "appropriate conditions, including possible financial terms or royalty- free conditions, taking into account the specific circumstances of the request for access, for example the actual or potential value of the results or background to which access is requested and/or the scope, duration or other characteristics of the exploitation envisaged"..$^{90}$ This definition applies to all the access situations described above. ${ }^{91}$

53 It is notable that, no matter whether the access requirements relate to members of the consortium or their affiliates, whether for fulfilling their tasks, for exploiting their own efforts, or as relates to third parties (in relation to interoperability), the access regime remains the same. One can assume that "fair and reasonable" was considered by the legislature as flexible enough to deal with this broad range of interests and situations. For this reason, the definition implies that conditions can change depending on the circumstances of the request for access (i.e. the nature of the parties), as well as depending on the subjective nature of value or "other characteristics". Again, while not using the expression "FRAND", it can be assumed that the nondiscriminatory aspect is included, as the definition specifically allows for differentiation where such a differentiation can be made.

\section{Vehicle Emissions Regulation}

54 European Regulation (EU) 715/2007, relating to emissions from light passenger and commercial vehicles and access to vehicle repair and maintenance information, contains a FRANDbased information sharing regime. It imposes specific obligations on vehicle manufacturers to enable access to vehicle repair and maintenance information both to authorised and independent dealers and repairers. ${ }^{92}$ Such access is on a nondiscriminatory basis while permitting manufacturers to charge a "reasonable and proportionate fee". ${ }^{93}$ However, the Regulation also notes that such fee is not reasonable or proportionate "if it discourages access by failing to take into account the extent to which the independent operator uses it", making it

90 Regulation 1290/2013, Article 2(1)(10).

91 Ibid, Article 25(3). Note that under Article 31, a distinction is drawn between royalty-bearing and royalty free, as these two options are given. However, logic would dictate that "fair and reasonable" includes royalty free in the range of royalties (as expressly noted in the definition of Article 25(3)) and because there are usually other material terms and conditions in licensing agreements that should also be fair, reasonable and non-discriminatory.

92 Vehicle Emission's Regulation, Article 7(1).

93 Ibid. clear that the fee also needs to be in proportion to the importance of the information to the user as well as a reasonable value to the manufacturer..$^{94}$

55 Although not using the exact "FRAND" wording, the Vehicle Emissions Regulation very much mirrors the FRAND intention of ensuring that fees are reasonable and non-discriminatory, while at the same time not discouraging access.

\section{Directive on Payment Services}

56 The revised Directive on Payment Services in the Internal Market ${ }^{95}$ of 25 November 2015 sets out that account servicing payment service providers, such as banks, must allow third parties to obtain real-time data relating to customers' accounts on a non-discriminatory basis (including without any discrimination in terms of charges, timing and priority). ${ }^{96}$ Colangelo and Borgogno query whether banks can charge a fee for the access to front-end third-party providers and speculate that such compulsory access can be compensated, "as it happens, mutatis mutandis, with standard essential patents that are licensed under fair, reasonable and non-discriminatory ("FRAND") terms". ${ }^{97}$ We agree that such access would be on the basis of FRAND principles, in accordance with the recognised commercial practices in the payment services field (rather than SEPs, per se). One can presume that where European regulation requires access to data and interoperability, such access must be on FRAND terms.

94 Regulation (EC) 715/2007 of the European Parliament and of the Council on type approval of motor vehicles with respect to emissions from light passenger and commercial vehicles (Euro 5 and Euro 6) and on access to vehicle repair and maintenance information [2007] OJ L 171/1. See also Benoit Van Asbroeck Julien Debussche Jasmien César, Building the European Data Economy \& Data Ownership, 1 January 2017. Available at <https://www.twobirds.com/en/news/ articles/2017/global/data-ownership-in-the-context-ofthe-european-data-economy>.

95 Directive (EU) 2015/2366 of the European Parliament and of the Council of 25 November 2015 on payment services in the internal market, amending Directives 2002/65/ EC, 2009/110/EC and 2013/36/EU and Regulation (EU) No 1093/2010, and repealing Directive 2007/64/EC (Text with EEA relevance)

96 Ibid, Articles 64-68.

97 Colangelo and Borgogno, Data, Innovation and Transatlantic Competition in Finance: The Case of the Access to Account Rule, Stanford-Vienna European Union Law Working Paper No. 35, 2018, <http://ttlf.stanford.edu>. Page 16 


\section{Credit Rating Agency Regulation}

57 The European Regulation 462/2013 of 21 May $2013^{98}$ amending Regulation No 1060/2009 on credit rating agencies included a FRAND-like requirement. As noted in recital 38 , fees charged by credit rating agencies to their clients should not be discriminatory, although charging for the same type of service to different clients can be justified by a difference in the actual costs in providing this service. New Article 3(c) goes further in setting costs parameters by requiring credit rating agencies to ensure that fees are based on the actual costs of providing the service and cannot be affected by either the level of the credit rating issued nor on any other result or outcome of the work performed. It would be logical to assume that costs for developing better software etc. would be included in the "actual" cost of assessing a customer's credit rating. Otherwise the incentive to improve credit rating services would be affected. In addition, recital 33 imposes a transparency and oversight requirement, requiring credit rating agencies to disclose to the European Securities and Markets Authority their general policies and fees received from each of their clients, in order to allow for the effective supervision of the rules.

\section{IX.EU Benchmarks Regulation}

58 The pricing of many financial instruments and contracts rely on the accuracy of benchmarks. However, following the serious manipulation of LIBOR, EURIBOR and other benchmarks by various cartels ${ }^{99}$ and the impact that the failure of critical benchmarks can have on market integrity, financial stability, consumers, the real economy, or the financing of households and businesses, the EU adopted the Benchmarks Regulation. ${ }^{100}$ Specifically to mitigate the market power of critical benchmark administrators and bring discipline to the market, the Regulation contains a FRAND regime imposing, under Article 22, the obligation on administrators of

98 Regulation (EU) No 462/2013 of the European Parliament and of the Council of 21 May 2013 amending Regulation (EC) No 1060/2009 on credit rating agencies Text with EEA relevance. OJ L 146, 31.5.2013, p. 1-33.

99 See e.g. Boot, Nuria and Klein, Timo and Schinkel, Maarten Pieter, Collusive Benchmark Rates Fixing (May 1, 2018). Tinbergen Institute Discussion Paper 2017-122/VII. Available at SSRN: <https://ssrn.com/abstract=3117398>.

100 Regulation (EU) 2016/1011 of the European Parliament and of the Council of 8 June 2016 on indices used as benchmarks in financial instruments and financial contracts or to measure the performance of investment funds and amending Directives 2008/48/EC and 2014/17/EU and Regulation (EU) No 596/2014 (Text with EEA relevance). OJ L 171, 29.6.2016, p. 1-65. See Recital 35. critical benchmarks, including critical commodity benchmarks, ${ }^{101}$ to take "adequate steps to ensure that licences of, and information relating to, the benchmark are provided to all users on a fair, reasonable, transparent and non-discriminatory basis". ${ }^{102}$ This requirement is without prejudice to the application of EU competition law.

\section{European Commission Policy Discussions for FRAND Access to Data}

59 The Commission is already considering the possibility of sharing the access to data between businesses, with FRAND access being one of the considered models. In 2017 the Commission published a Communication entitled "Building a European Data Economy". In relation to access to data, the Commission explored the idea of applying a FRAND regime, whereby access to machine generated data would be granted against remuneration. ${ }^{103}$ The Communication notes that: "A framework potentially based on certain key principles, such as fair, reasonable and non discriminatory (FRAND) terms, could be developed for data holders, such as manufacturers, service providers or other parties, to provide access to the data they hold against remuneration after anonymisation. Relevant legitimate interests, as well as the need to protect trade secrets, would need to be taken into account. The consideration of different access regimes for different sectors and/or business models could also be envisaged in order to take into account the specificities of each industry. For instance, in some cases, open access to data (full or partial) could be the preferred choice both for firms and for society." 104

101 Ibid, Recital 38

102 See also, for example, the UK Financial Conduct Authority policy statement also requiring regulated benchmark administrators to grant access to and licenses to use benchmarks on a FRAND basis See PS16/4, February 2016. For example, para 1.9 states "In summary, our proposals required regulated benchmark administrators to grant access to and licences to use benchmarks on a fair, reasonable and non-discriminatory basis, including with regards to price. We proposed that such access should be provided within three months following a written request. We proposed that different fees should be charged to different users only where this is objectively justified, having regard to reasonable commercial grounds such as the quantity, scope or field of use requested. Our proposals also set out a list of non-exhaustive factors that we may consider in assessing whether the terms of access to a benchmark are FRAND".

103 European Commission, Towards a common European data space (Communication), COM(2018) 232 final.

104 Ibid, page 13. 
60 The Communication highlights that a FRAND regime is business model neutral, recognising that data will have a value to the owner, while permitting both remuneration-based, as well as free access, and is flexible enough to take different sectorial interests and regulatory parameters (in this case anonymisation) into account. The Staff Working Document (SWD) accompanying the Communication acknowledges that inspiration can be found across a range of instruments, including some of those explored in the sections above. ${ }^{105}$

61 Following a public consultation, the Commission in 2018 published a Guidance on Sharing Private Sector Data in the European Data Economy. ${ }^{106}$ It recommended companies to consider voluntarily granting access to non-personal data to other businesses and, when doing so, to adhere to certain principles related to transparency, respect to each other's commercial interests, to ensure undistorted competition, and minimise lock-in. ${ }^{107}$ The Commission at least appears to recognise that the problems raised by big data and dominant digital platforms could be resolved by some form of data sharing requirement on principles that mirror notions protected by the FRAND regime.

\section{F. The Nature of FRAND under European Law}

62 We see FRAND-based access regimes applied by European legislation across multiple sectors and activities, fostering the sharing essential technologies or access to critical inputs in both regulated and unregulated sectors. These FRAND access regimes are imposed to promote various public interests relating to both private and public sector bodies. The nature of the entities that control

105 European Commission Staff Working on the free flow of data and emerging issues of the European data economy. Accompanying the document. Communication Building a European data economy, 10.1.2017 SWD(2017) 2 final. A number of academics such as Drexl (footnote 56) or Daniel L. Rubinfeld \& Michal Gal (see Access Barriers to Big Data (August 26, 2016). 59 Arizona Law Review 339 (2017). Available at SSRN: <https://ssrn.com/abstract=2830586> or <http://dx.doi.org/10.2139/ssrn.2830586>) also seized upon FRAND as a model to replicate in the data context. Van Asbroeck, Debussche \& César (footnote 95) argue at p 85, that "Providing more favourable access conditions in case of sole-source databases could be a particularly interesting course of further analysis. It could also be examined whether some of the outstanding access to data issues could be solved by using open licences allowing for commercial re-exploitation and re-utilisation of the information on fair and non-discriminatory terms."

106 European Commission, Guidance on Sharing Private Sector Data in the European Economy (Communication), SWD(2018) 125 final.

107 Ibid, p.3. the critical input is also varied. In some instances, the entities may possess or are likely to possess market power, in other instances the input is critical for market activity yet not necessarily critical to market access. In some instances, FRAND is applied in the context of disputes with particular steps in order to ensure access on reasonable terms. This shows the flexibility of the FRAND regime, which can apply to different players and in different circumstances.

63 The core elements of a FRAND regime can be summarised. At a high level, the purpose of the FRAND regime is to ensure broad and nondiscriminatory access to the relevant input. Where legal relations need to be regulated, such access will often be though a license or similar agreement, but where access is guaranteed, a separate agreement may not be required. Its aim is to ensure the widest possible market access and use of the input, while avoiding lock-in, hold up, or foreclosure.

64 From the regulatory FRAND examples highlighted above, the Standardisation Regulation and EECC expressly refer to the term "fair, reasonable and non-discriminatory" while leaving the details of the arrangement to the market. The other examples use access regimes that are essentially identical to FRAND in all but the express wording, creating FRAND-based conditions of balance, reasonableness, non-discrimination and transparency. In fact, it is arguable that the FRAND regime used by the European institutions is a general principle and that a FRAND policy need not reflect those exact words, in that exact order, in order to achieve the same result. It would be difficult to argue that those laws that do not use the exact expression "FRAND" somehow grant access on a significantly different basis.

65 The various examples of European regulation each provide, to some degree, greater guidance on the detail FRAND-like regimes, displaying significant consistency across the board. In particular:

- Fair \& Reasonable balance: Legislation covering REACH, the European Vehicle Emissions Regulation, the Public Sector Information Directive and the Horizon 2020 Regulation, provide parameters and guide points on calculating payment ("compensation", "income", "charge", "financial terms"), emphasising the balance between costs/ investment over use/access and reflecting the different interests of the parties.

- Transparency: In addition, the Re-use of Public Sector Information Directive focuses on transparency of terms and conditions, including (on request) the calculation basis for the fee, mirroring Huawei $v$ ZTE requirements for FRAND licensing of SEPs. In REACH and Huawei $v$ ZTE, 
both the holder of the critical input and the user have an obligation to find a fair and reasonable result.

- Non-Discrimination: In the Re-use of Public Sector Information Directive, public sector bodies will not discriminate if they grant free access to another public body fulfilling a public sector task, while commercial parties can be charged for the re-use of the same documents. The Horizon 2020 Regulation applies a "fair and reasonable" definition that enables differentiation where this can objectively be made (and it can therefore be assumed that nondiscrimination is implicitly included).

- Dispute Resolution: In order to achieve the FRAND balance, there is an obligation on both parties to act in good faith. That is expressly set out in REACH, Huawei $v$ ZTE framework for SEPs, and implied in Horizon 2020, which refers to fair and reasonable access being granted "subject to agreement". In the event of intractable disagreement, various forms of dispute resolution are available including the involvement or regulatory agencies, arbitration and mediation, but always preserving access to courts in the final instance.

66 Other notable points that underpin FRAND include: fostering access (the EECC focuses on the broad availability and variety of programming and services or Horizon 2020 access to research results); promoting key elements found in all FRAND frameworks (efficiency, competition, investment, innovation, consumer welfare); and favouring bilateral, marketbased contractual negotiations over government intervention, within the parameters set out in the legislation.

67 Therefore, the review of FRAND access remedies in EU legislation shows that the public interest can underpin access regimes providing an ex ante framework which competition and regulatory policy can support, given the limitations of competition law in ex post market correction. While there are calls for ex ante common carrier or public utility regulation, ${ }^{108}$ it is clear that well-articulated public interest criteria can be the basis of a FRAND regime, which will take a balanced, proportionate and pragmatic approach to the sharing of critical or important resources without the need for treating at least dominant platforms' activities as essential facilities or public utilities. ${ }^{109}$

108 Khan (2017), page 797 et seq. See footnote 5.

109 "There is also a case for considering new ex ante regulatory tools to enhance the competitive process in digital platform markets: standards and interoperability, data portability, consumer transparency, and algorithmic pricing. In each of these, the challenge is translating well-established

\section{G. The relevance of a FRAND access regime to dominant digital platforms}

68 Having discussed the usability of FRAND access regimes in EU legislation and competition cases, the next issue to be assessed is its relevance for dominant digital platforms. A FRAND access regime can be useful in resolving issues both in relation to access to essential data and access to platforms. As seen, the application of competition law to ensure access to data considered essential for conducting business held by dominant platforms, may not be adequate to ensure full and timely access. Providing access to critical data on FRAND terms could be a way of fostering competition, but also protecting the interests and incentives to innovate digital platforms. Moreover, FRAND access can also be relevant in cases when dominant digital platforms refuse to provide access to its platform to rivals.

69 Calculating what precisely FRAND terms are may not be straight forward, and assessing "fair and reasonable" in the abstract remains complex. ${ }^{110}$ There are numerous economic theories proposed for assessing the value for accessing technology, some of which purport to be FRAND-specific. ${ }^{111}$ Not only do sectors and inputs differ (including, importantly, the legal regime governing them) but parties will have subjective notions of value, which is influenced by their different needs and incentives. This was recognised in the Horizon 2020 Regulation's

principles of competition analysis, law, and enforcement practice into the new domain of digital platforms". Coyle (2018), p. 17. See footnote 8.

110 Concerns about FRAND are often coloured by the very public disagreements over FRAND royalty rates for essential patents. See for example Denis Carlton, Allan Shampine, 'An Economic Interpretation of FRAND' (2013) 9 Journal of Competition Law \& Economics 531 (arguing for the use of ex ante incremental value of the patent before it was included in a standard); and Gregory Sidak, 'The Meaning of FRAND, Part I: Royalties' (2013) 9 Journal of Competition Law \& Economics 931 (criticising the use of ex ante incremental value approach and suggesting the use of comparable licenses as a best indicator of a patent's market value). However, there are key distinctions between the regulation of FRAND regimes for digital platforms and the private ordering system under FRAND-based standardisation. First, the key input in standardisation (the technological specifications making up the standard and the patents that protect these essential technologies) are publicly available, so that it is therefore possible, and indeed usual practice, for the technology to be implemented before licensing terms are agreed. This can lead to gaming of the system with the SEP holder playing "catch up". However, in the context of regulated access, agreement on terms should occur before access is granted.

111 See Norman Neyrinck, The Value of Intangibles - Remedies for Abuse of Refusal to License, Working Paper. P. 45. Available at <http://www.emulation-innovation.be/wp-content/ uploads/2013/09/Remedies-for-Abuse-of-Refusal-toLicense-Norman-Neyrinck-22-11-2010.pdf>. 
definition of "fair and reasonable conditions", accepting that conditions could change depending on the position of the parties; i.e. the circumstances of the access request, the nature of value of the input, or other characteristics. Having said that, metrics do have an important role to play in terms of transparency purposes, when the parties are not able to reach a compromise or where terms need to be determined by a third party. Such a third party, whether a regulator, court, arbitrator or mediator, will need to be informed by valuation principles and modelling. ${ }^{112}$

70 Assessing FRAND terms begins with an understanding of the nature of the input and relevant ecosystem. Some of the FRAND-based regulations are distinguished by the multiplicity of players involved in granting access to essential input that they control. One such example is REACH where we see common base formulae across product markets, applying per-tonnage fixed-fee price bands per substance. ${ }^{113}$ Clearly each sector will have different considerations attached to them. FRAND metrics discussed for access to e.g. public data, publicly funded project results, standard essential technologies or access to API, are not interchangeable.

71 However, this paper shows that there are general principles that narrow down the discussion and concentrate the mind. Value considerations for access to dominant digital platform inputs are not impossible to explore. Looking at FRAND licensing commitments made by dominant platforms in merger cases, provides a useful insight into different means to assess FRAND.

72 For example, in Worldline/Equens, the remedies actually set out that the pricing of Poseidon licensing terms, which are structured around three main aspects, i.e. reference modules for which a price list is provided to NSPs to serve as a basis for bilateral negotiations; software maintenance fees, reference to a percentage of the license fee paid by NSPs (adjusted annually); and fees for ad hoc support services, set by reference to an hourly rate (adjusted annually). We therefore see that FRAND principles focus on providing transparent pricing, which can be the focus of negotiations and, where needed, adjudicated. The role of the Licensing

112 What is clear is who chooses the metrics to use in order to determine the access terms, is as important as the metrics themselves. This narrows choices down in determining the terms themselves (usually the parties). But the oversight mechanism - who monitors the agreements and who adjudicates disputes (and their powers) - is equally critical in ensuring parties do not game the system.

113 See for example the European Chemical Industry Council (CEFIC) guidance for its Substance Information Exchange Forum at <https://cefic.org/app/uploads/2019/01/Fairand-transparent-cost-sharing-in-SIEFs_REACHImpl_Legal. pdf>.
Trustee is therefore a significant element, as is their need to have access to all of Worldline licenses in order to adjudicate on disputes. Nor does FRAND necessarily relate to the "price" of one input, but rather to all elements that are needed to ensure effective access, including maintenance, additional modules and upgrades. For this reason, the Worldline/ Equens remedies also included various flanking commitments. ${ }^{114}$

73 In Newscorp/Telepiu, FRAND pricing for access to the API is to be determined by the lowest of the prices obtained when applying the two following principles: “(i) cost-oriented basis adopting where appropriate a long-run incremental costs approach and including a fair and reasonable contribution to the investment costs of set-top box roll-out and related infrastructure plus a reasonable return and (ii) relevant market values (where they exist) for comparable services." 115 It is notable that the Commission was willing to rely on two calculation methods: one economic model that factors both investment costs for implementation and return to the API holder; and one focusing on existing market comparables. However, rather than averaging out the rate, the policy choice was made to accept the lowest of the two.

74 One of the metrics that tends to have uniform acceptance and is reflected in both the Worldline/ Equens and Newscorp/Telepiu remedies, is the use of comparable agreements or a track record of agreements. In the context of dominant digital platforms providing FRAND access, a question arises where there are no agreements that can act as precedent. The various FRAND metrics that can be considered cannot be divorced from the central question: "what can both parties live with?"116

75 Finally, it is also clear that FRAND cannot merely mean "cheap"; such an approach would disincentivise investment in developing innovative technology solutions and, perversely, condemn the most successful technologies to be less valuable. The FRAND regime reflects the balance between the importance of ensuring easy access to an input, while ensuring that the holder of the input is fairly remunerated. This means agreeing to a value that does not inhibit access but that also recognises, in addition to the value of technology, R\&D costs,

114 See footnote 26.

115 See footnote 24. Part II, para 11.6.

116 But it is also true that, depending on the circumstances and nature of the parties, the financial terms may be only one consideration. A FRAND regime includes within its notion of fairness and reasonableness royalty-free and other nonmonetary considerations provided by the user for access, as well as important terms and conditions, which must be both fair, reasonable and non-discriminatory for access to the input. 
risks taken, cost of capital etc. in order to incentivise future R\&D projects. ${ }^{117}$ Therefore the choice of the appropriate pricing methodology becomes a policy choice, as where to strike the right balance between fostering upstream or downstream innovation. ${ }^{118}$

\section{H. Conclusion: A FRAND policy for Dominant Digital Platforms?}

76 This paper has shown that there are numerous examples of the FRAND regime being used in European law, regulation and policy to ensure that critical inputs become or remain accessible to third parties. In fact, European regulation relating to access to critical inputs often appears to coalesce around FRAND access principles. A FRAND access regime would therefore have many benefits in addressing issues raised in markets where companies may play a gatekeeper function, such as digital platforms. Indeed, the FRAND regime has already guaranteed interoperability with broader ecosystems and thirdparty applications, as well as fair access to critical online platforms. At the same time, it allows fair compensation for the sharing of technology, thereby encouraging further investment in future innovation and competition in other markets. It can also be used to maintain APIs for third party access and can ensure access to data which is of great importance to a competitive and dynamic digitalisation of the European economy.

77 When elaborating policies related to digital platforms and/or data, the European Commission could seek inspiration from these sources. The FRAND regime is inherently flexible and indeed business-model neutral as it creates a level playing field between players on recognised commercial terms. Although the form that an access remedy should take depends on the nature of the input - both its physical nature (in this case non-tangible) and its legal nature the FRAND regime side-steps many regulatory difficulties by creating an overarching model. ${ }^{119}$ While public policy may set out various parameters for the sector input in question, terms and conditions of access, in their broadest sense, are left to bilateral market-based negotiations between participants in their particular market context with a dispute resolution or judicial backstop. In other words, FRAND enables the maintenance of competitive conditions, according to existing industry norms and

117 See e.g. European Commission, Setting out the EU approach to Standard Essential Patent (Communication), COM(2017) 712 final, 29 November 2017.

118 See Neyrinck (2010), footnote 112.

119 See Jacopo Ciani, Governing Data Trade in Intelligent Environments: A Taxonomy of Possible Regulatory Regimes Between Property and Access Rights, Intelligent Environments 2018285 in I. Chatzigiannakis et al. (Eds.). practices, minimising disruptions and ensuring that regulatory solutions are as seamless and as limited as possible.

78 The implementation of a FRAND access regime may be voluntarily adopted ex ante by emerging digital platforms, before network effects become entrenched. Having in place access regimes to enable new entrants to compete on or for the market would be a preventative measure forestalling competition scrutiny. Competition law guidance would be beneficial in providing some legal certainty on the scope of such a remedy in competition law, for example creating a safe harbour where platforms undertake to provide access of FRAND terms and based on the European Commission's practice. This can be supplemented by ad hoc competition law enforcement to ensure access where competitive harm might otherwise occur. Moreover, while competition enforcement may not be able to resolve all of the issues raised by dominant digital platforms, competition policy can play an important supporting function in enforcement, policy and advocacy.

79 Alternatively, such access can be mandated by future legislation. Subjecting the platform to FRAND access provisions prevents the need to engage in regulated access expost, as FRAND terms are market based. From an industrial policy perspective, however, the public interest tests elaborated in existing FRAND-based legislation are instructive in moving undertakings to adopt FRAND-based access. Therefore, while regulators deliberate dominant digital platforms, FRAND regimes can be considered as an effective access framework beyond the classic notions of market power.

80 This brief review of European regulation and policy should provide comfort and inspiration that a FRAND-based approach can ensure fair access to relevant platforms and services, in order to enable effective competition and fulfil European public interests. Regulation and competition policy will need to work hand in hand in identifying coherent regulatory approaches. Competition policy can assist European policy makers to engage in a more coherent manner by providing guidance for dominant digital platforms to adopt voluntary FRAND commitments and be consistent in the use of FRAND-based remedies, where appropriate. 